\title{
Alfred Gierer
}

Model for DNA protein interactions and the mode of action of the operator

(Reprinted from Nature, Vol. 212, No. 5069, pp. 1480-1481, December 24, 1966) 
(Reprinted from Nature, Vol. 212, No. 5069, pp. 1480-1481,

December 24, 1966)

\section{A Model for DNA-Protein Interactions and the Mode of Action of the Operator}

THE regulation of gene activity seems to depend, at least partially, on specific interactions between DNA and protein. In particular, regulation of protein synthesis in bacteria is probably determined by interaction between operator genes and proteins acting as repressors ${ }^{1}$. It is conceivable that the proteins interact directly with specific sequences of nucleotides in the groove of doublestranded DNA².

There is, however, another possibility suggested by the recent determination of the structure of transfer $\mathrm{RNA}^{3}$. This single-stranded RNA is known to fold back on itself and to give rise to several small double-stranded regions where complementary bases are paired. The secondary structure which results contains branches and loops which are probably responsible for the specific interaction with protein, in this case with the amino-acid-activating enzyme.

A somewhat analogous model can be postulated for the interaction of DNA and protein. If each strand of doublestranded DNA contains sequences of nucleotides $x_{1}$, $\mathbf{x}_{2} \ldots . \mathbf{x}_{\mathbf{n}}$, followed first by a few nucleotides $\mathbf{x}^{\prime}, \mathbf{x}^{\prime \prime}$, $\mathrm{x}^{\prime \prime \prime}$... and then by a sequence complementary to $\mathrm{x}_{1}$, $\mathrm{x}_{2} \ldots \mathrm{x}_{\mathrm{n}}$, but in reversed order, an equilibrium between the normal double-stranded structure of DNA $(A)$ and a branched structure $(B)$ containing segments of DNA strands folded back on themselves (Fig. la) would be expected. More complicated structures would also be possible; there could be several consecutive branches on the DNA, and the primary branches might contain secondary and tertiary branches (Fig. $1 b$ ). It is postulated that branched structures $(B)$ may determine specific interactions between DNA and protein.

In general, structure $B$, containing a few unpaired nucleotides, would be expected to be less stable than structure $A$. Protein, however, may stabilize structure $B$ by association with the DNA, particularly if there is some specificity of interaction with the loop containing unpaired nucleotides. Such an association might be involved in the repression or activation of gene function. For example, a branched region of DNA containing the operator may be stabilized by repressors to block starting sequences for the synthesis of messenger RNA. It is conceivable that there are chemical modifications of unpaired nucleotides which help to shift the equilibrium toward conformation $B$, making an operator more readily accessible to repressors. 


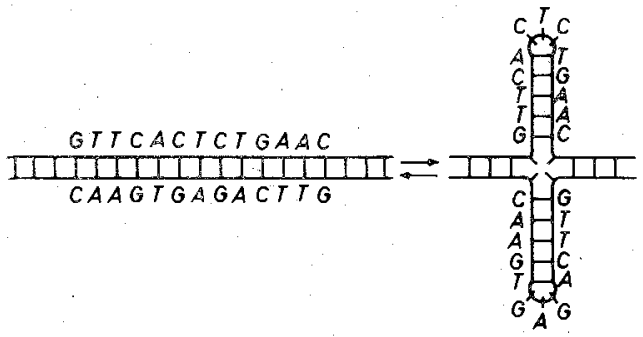

(A)

(B)

$a$

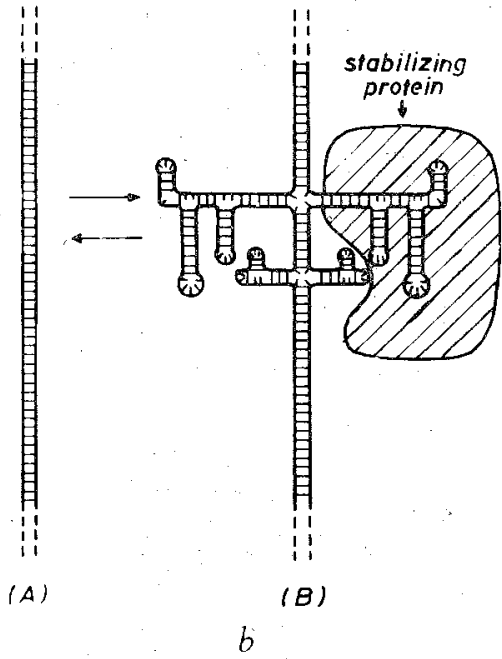

Fig. 1. Equilibrium between continuous double-stranded DNA (structure $A$ ) and branched DNA (structure $B$ ). Unpaired nucleotides are only schematically indicated. There may be structural requirements for additional unpaired nucleotides in structure $B$. (a) Example of a simple branched DNA; (b) example of DNA with secondary branches.

The model could possibly be applied to other problems. For examplo, some loops could be susceptible to specific enzymes such as DNases and methylating enzymes responsible for host-specific sensitivity and stability of DNA ${ }^{4}$. The spatial arrangement of DNA in chromosomes might partially derive from branched structures of DNA stabilized by proteins.

Experiments to test the hypothetical model can be based on the prediction that the branches contained in structure $B$ should be formed by denatured, singlestranded DNA even without external stabilization. Some base-pairing in single-stranded denatured DNA has been 
demonstrated ${ }^{3}$. One might expect that denatured DNA would in some cases be more suited to detect the specific interaction with protein than native DNA.

I thank Dr. Friedrich Bonhoeffer for stimulating discussions.

ALFRED GIERER

Max-Planck-Institut für Virusforschung,

Tübingen, Germany.

${ }^{1}$ Jacob, F., and Monod, J., J. Mol. Biol., 3,318 (1961).

${ }^{2}$ Wilkins, M. H. F., Biochem. Soc. Symp., 14, 13 (1957).

${ }^{3}$ Holley, R. W., Apgar, J., Everett, G. A., Madison, S. T., Marquisee, M., Merill, s. M., Penswick, J. A., and Zamir, A., Science, 147, 1462 (1965).

* Arber, W., J. Mol. Biol., 11, 247 (1965).

5 Walker, P. M. B., and McLaren, A., Nature, 208, 1175 (1966). 